\title{
A voz da mulher imigrante no debate público sobre o 'Projeto pró-cesárea no SUS' em São Paulo a partir da perspectiva da comunicação intercultural
}

\author{
The immigrant women voice in the public debate about the 'Pro-Cesarean \\ Project in SUS' in São Paulo city from the perspective of intercultural \\ communication
}

\section{La voz de las mujeres inmigrantes en el debate público sobre el 'Proyecto Pro Cesárea en elSUS' en São Paulo desde la perspectiva de la comunicación intercultural}

\author{
Camila Escudero ${ }^{1, a}$ \\ camila.escudero@metodista.br | http://orcid.org/oooo-0002-9399-1207 \\ ${ }^{1}$ Universidade Metodista de São Paulo. São Paulo, SP, Brasil. \\ a Doutorado em Comunicação e Cultura pela Universidade Federal do Rio de Janeiro.
}

\section{Resumo}

Este artigo, de caráter interdisciplinar, tem como objetivo articular questões da diversidade sociocultural com o direito à comunicação e à saúde e a estratégias de reconhecimentos identitários. Para isso, propomos uma análise de conteúdo, de abordagem qualitativa, da comunicação produzida pela Equipe de Base Warmis - Convergências das Culturas sobre o caso que ficou conhecido como Projeto pró-cesárea no SUS ou PL 435/2019, comparando-a ainda com matérias veiculadas sobre o tema na mídia tradicional comercial e em notas e comunicados oficiais de instituições formais de classe profissional envolvidas com a questão. Como recurso teórico-metodológico, utilizamos os conceitos de interculturalismo e comunicação intercultural. Entre os principais resultados, destacamos que processos comunicacionais, quando entendidos não somente a partir de seu alcance instrumental, mas, em seu sentido de vinculação sociocultural, interação simbólica e produção subjetiva, podem ter caráter mobilizador coletivo e de reconhecimento identitário visando, muitas vezes, a transformação da realidade social, ainda que essa signifique uma coexistência sociocultural capaz de ser negociada.

Palavras-chave: Comunicação intercultural; Imigrantes em São Paulo; Interculturalismo; Saúde; Mobilização social.

\section{Abstract}

This interdisciplinary article aims to articulate issues of sociocultural diversity with the right to communication and health and identity recognition strategies. For this, we propose a qualitative content analysis about the communication produced by the Warmis Base Team - Convergences of Cultures on the case known as the Pro-cesarean project in SUS or PL 435/2019, comparing it with articles published about the theme in 
the traditional commercial media and in formal professional class institutions official notes involved with the case. As a theoretical-methodological resource, we use the interculturalism concept and intercultural communication. Among the main results, we highlight that communicational processes, when understood not only from their instrumental reach, but, in their sense of sociocultural attachment, symbolic interaction and subjective production, can have collective mobilizing character and identity recognition, often aiming at the transformation of social reality, even if it means a sociocultural coexistence able of being negotiated.

Keywords: Intercultural communication; Immigrants in São Paulo city; Interculturalism concept; Health; Social mobilization.

\section{Resumen}

Este artículo, interdisciplinario, tiene como objetivo articular temas de diversidad sociocultural con el derecho a la comunicación y a la salud y estrategias de reconocimiento de identidad. Para esto, proponemos un análisis de contenido cualitativo de la comunicación producida por el Equipo Base de Warmis - Convergencias de las Culturas en el caso conocido como el Proyecto pro cesárea en SUS o PL 435/2019, comparándolos con artículos publicados sobre el tema en los medios comerciales tradicionales y con notas oficiales de instituciones formales de clase profesional involucradas en el tema. Como recurso teórico-metodológico, utilizamos los conceptos de interculturalidad y comunicación intercultural. Entre los principales resultados, destacamos que los procesos comunicacionales, cuando se entienden no solo desde su alcance instrumental, sino que, en su sentido de apego sociocultural, interacción simbólica y producción subjetiva, pueden tener un carácter movilizador colectivo y reconocimiento de identidad, con el objetivo de la transformación de la realidad social, aunque esa signifique una convivencia sociocultural capaz de ser negociada.

Palabras clave: Comunicación Intercultural; Inmigrantes en São Paulo; Interculturalidad; Salud; Movilización social.

Este artigo compõe o Dossiê Saúde, etnicidades e diversidade cultural: comunicação, territórios e resistências.

Contribuição dos autores: a autora é responsável por todo o texto.

Declaração de conflito de interesses: não há.

Fontes de financiamento: Os recursos teóricos-metodológicos utilizados neste artigo, bem como o próprio objeto, fazem parte de uma pesquisa mais ampla, intitulada 'A natureza das experiências e dos contextos de práticas midiáticas envolvendo imigrantes na cidade de São Paulo', que vem sido desenvolvida pela autora desde o início de 2019 com o apoio da Fapesp (Auxílio Regular de Pesquisa) e CNPQ (Chamada Universal).

Considerações éticas: não há.

Agradecimentos/Contribuições adicionais: não há.

Histórico do artigo: submetido: 11 ago. 2019 | aceito: 8 nov. 2019 | publicado: 20 dez. 2019.

Apresentação anterior: não houve.

Licença CC BY-NC atribuição não comercial. Com essa licença é permitido acessar, baixar (download), copiar, imprimir, compartilhar, reutilizar e distribuir os artigos, desde que para uso não comercial e com a citação da fonte, conferindo os devidos créditos de autoria e menção à Reciis. Nesses casos, nenhuma permissão é necessária por parte dos autores ou dos editores. 


\section{Introdução}

A complexidade dos processos migratórios internacionais atuais tem evidenciado a necessidade de se propor modelos de estudos abrangentes e interdisciplinares. Trata-se da superação da divisão dos deslocamentos em categorias analíticas pré-estabelecidas, disciplinas únicas e aspectos metodológicos fechados que, ao enfatizar as diferenças entre os campos de conhecimento, costumam isolar a rica diversidade sociocultural e heterogeneidade envolvidas na temática, colocando em segundo plano a compreensão de aspectos subjetivos, conhecimentos de ordem das relações humanas, das organizações sociais e das identidades.

Assim, o presente artigo tem como objetivo aproximar os campos dos estudos migratórios, da comunicação e da saúde, com o desafio maior de articular questões da diversidade sociocultural com o direito à comunicação e à saúde e a estratégias de reconhecimentos identitários. Nesse sentido, apresentamos o seguinte problema de pesquisa: de que maneira os processos comunicacionais podem ter caráter mobilizador coletivo e de reconhecimento identitário visando, muitas vezes, a transformação da realidade social a partir de uma perspectiva intercultural?

Para responder a essa pergunta, propomos uma análise de conteúdo, de abordagem qualitativa, conforme as considerações de $\operatorname{Bardin}^{1}$ e Krippendorf ${ }^{2}$, da comunicação produzida pela Equipe de Base Warmis Convergências das Culturas sobre o caso que ficou conhecido como 'Projeto pró-cesárea no SUS' ou 'PL 435/2019', uma proposta da deputada estadual Janaína Paschoal (PSL) prevendo a garantia às gestantes do Sistema Único de Saúde (SUS) a opção pelo parto cirúrgico (cesárea) a partir da 39 a semana de gestação, sem a necessidade de indicação clínica para o procedimento.

O corpus de análise é composto por conteúdo veiculado pela Equipe Base Warmis em seus canais oficiais de comunicação (sites, página do Facebook, blog etc.), matérias publicadas sobre o tema na mídia tradicional comercial e notas e comunicados oficiais de instituições formais de classe profissional que estão, de alguma maneira, envolvidas com a temática e se pronunciaram a respeito da questão.

Como recurso teórico-metodológico, utilizamos os conceitos de interculturalismo e comunicação intercultural. O primeiro é compreendido aqui como um aparato simbólico pelo qual o sujeito dá sentido a práticas e relações sociais, ou seja, o reconhecimento do 'outro' (alteridade) possibilita que relações de contato e troca cultural se efetivem em grupos diferentes para que, justamente, esses possam se reelaborar, garantindo assim sua inserção em um mundo acelerado pela lógica da globalização. O segundo aponta para uma dimensão da prática comunicacional não apenas na sua acepção instrumental de veiculação, transmissão e/ou representação, mas principalmente, em suas conotações de vinculação social, interação simbólica e produção subjetiva.

\section{O conceito de interculturalismo nos estudos migratórios: breves apontamentos}

De abordagem interacionista, podemos dizer que a perspectiva interculturalista evidencia os modos de organização social, porém, privilegiando aspectos culturais dos sujeitos envolvidos em um quadro histórico e geopolítico amplo, marcado, nos nossos dias, pela aceleração dos fluxos informacionais e comunicacionais. "As pesquisas [interculturais] concentraram-se em delinear a gênese e reprodução das formações sociais transnacionais, bem como os contextos macrossociais específicos em que essas formações sociais transfronteiriças têm operado"3.

Cogo relaciona a origem do termo intercultural ao campo da Educação e a uma crítica aos conceitos de multiculturalismo (ou multiculturalidade) e pluralismo, insuficientes para a reflexão da dinâmica de novos arranjos socioculturais. Pensa-se, nesse momento inicial, nas interações educativas em ambientes escolares, especialmente no contexto europeu dos anos 1960 e 1970, que não poderiam ser reduzidas somente à soma ou coexistência de culturas diferentes. "A interculturalidade envolve, assim, a ideia de 'nova 
síntese cultural' em que o projeto de sociedade intercultural supõe a geração intencionada, planificada ou induzida de algo novo, de expressões culturais novas. O que chama atenção aqui não é tanto a defesa do direito à diferença e a crítica de modelos de assimilação, fusão etc. que implicariam a perda de uma cultura própria, mas sua menção a que esses modelos originais - elaborados no projeto intercultural a partir das culturas em presença - se incorporariam à cultura nacional de base reforçada e renovada"4.

A partir da Educação, o conceito se estendeu gradativamente para outros campos (Antropologia, Psicologia, Sociologia etc.), popularizando-se. Ainda de acordo com Cogo, isso ocorreu não como fato ou fenômeno, mas como uma proposta de atuação, devido a uma "busca permanente por uma terminologia mais adequada para descrever, a partir de uma perspectiva propositiva, a rica e conflitiva interação entre distintos segmentos socioculturais"4.

Canclini relaciona o conceito de interculturalidade à mistura de sujeitos e sociedades, ou seja, ao que acontece quando as diferenças se encontram, convivendo em situações de negociações e trocas recíprocas. Tal situação ganha relevância não só dentro de uma etnia ou nação, mas em "circuitos globais, superando fronteiras, tornando porosas as barreiras nacionais ou étnicas e fazendo com que cada grupo possa abastecer-se de repertórios culturais diferentes”, em uma reelaboração intercultural do sentido de práticas subjetivas e culturais.

Dessa maneira, Canclini chama os produtos resultantes da interface entre grupos culturais distintos de hibridação, termo escolhido para "designar as misturas interculturais propriamente modernas, entre outras, aquelas geradas pelas integrações dos Estados nacionais, os populismos políticos e as indústrias culturais" ${ }^{\text {. Para o }}$ autor, a hibridação seria o termo adequado para traduzir os processos derivados da interculturalidade, não só as fusões raciais comumente denominadas de mestiçagem, ou o sincretismo religioso, mas também as misturas modernas do artesanal com o industrial, do culto com o popular e do escrito com o visual, ou seja, trata-se de um conceito de maior amplitude e atualidade que explicaria melhor os complexos processos combinatórios contemporâneos. "Historicamente, sempre ocorreu hibridação, na medida em que há contato entre culturas e uma toma emprestados elementos das outras. No mundo contemporâneo, o incremento de viagens, de relações entre as culturas e as indústrias audiovisuais, as migrações e outros processos fomentam o maior acesso de certas culturas aos repertórios de outras. [...] Em todo esse contexto vemos que os processos de hibridação são uma das modalidades de interculturalidade, mas a noção de interculturalidade é mais abrangente, inclui outras relações entre as culturas, intercâmbios às vezes conflitivos"

Nos estudos migratórios, a questão intercultural tem origem (ainda que não necessariamente com essa terminologia) já a partir do século XX, quando a observação, análise e consequências da realidade decorrente da crescente mobilidade populacional da Europa, em crise e em guerras, para os países da América (o Novo Mundo), particularmente os Estados Unidos, fizeram com que os cientistas sociais passassem a tratar da imigração como uma questão principal em seus estudos. Assim, os processos migratórios deixam de aparecer como uma preocupação secundária, relacionada a outras ocorrências econômicas e sociais especialmente, como consequência do desenvolvimento do capitalismo (industrialização, urbanização, mobilidade populacional etc.) -, e ganham papel de protagonista.

Uma das bases iniciais para essa nova perspectiva são as ideias de Simmel, que apresenta o texto O Estrangeiro, em 1908, no qual discute a situação do imigrante (nomeado "estrangeiro"»), não mais como "aquele que vem hoje e amanhã se vai, mas como o que vem hoje e amanhã pode permanecer"», ou seja, uma figura social distante que se torna próxima. “O estrangeiro, contudo, é também um elemento do grupo, não mais diferente que os outros e, ao mesmo tempo, distinto do que consideramos como o 'inimigo interno'. É um elemento do qual a posição imanente e de membro compreendem, ao mesmo tempo, um exterior e um contrário"8.

Outra base para essa mudança de posicionamento reside também no "outro estrangeiro", o de Schütz Em um artigo publicado originalmente em 1955, o autor define estrangeiro como o indivíduo adulto do nosso tempo e civilização que tenta ser permanentemente aceito ou, ao menos, tolerado pelo grupo do qual ele se aproxima. O autor foca sua análise no que classifica de "típica situação", aquela em que um estrangeiro 
se encontra no seu esforço de interpretar o padrão cultural de um grupo social do qual se aproxima para orientar-se dentro dele. Trata-se de uma situação de aproximação que precede todo possível ajustamento social e que, somente após, tendo reunido um determinado conhecimento da função interpretativa do novo padrão cultural, o estrangeiro pode começar a adotá-lo como esquema de sua própria expressão.

Outras contribuições fundamentais para o desenvolvimento do interculturalismo no campo dos estudos migratórios são a Escola de Chicago (1910 - 1940) e os Estudos Culturais (1964). A primeira carrega a responsabilidade de ter transformado o tema da imigração em um problema sociológico, utilizando abordagens epistemológicas semelhantes na compreensão das particularidades dos deslocamentos ${ }^{10}$. Já a segunda surgiu com o objetivo principal de estudar a relação entre a sociedade e as mudanças sociais, observando formas, atividades práticas, instituições culturais e suas relações com a sociedade e a transformação da cultura. Tradicionalmente entendida pelos marxistas como algo pertencente ao campo das ideias, a cultura passa a ser vista como não dependente das relações econômicas, mas fruto das relações políticas e econômicas e recriada a todo momento (reflexo das relações de produção e da estrutura econômica). Trata-se de uma contribuição teórica e metodológica que resultou em uma transformação radical do conceito de cultura, uma vez que esta passou a englobar significados e práticas concretos e efetivos por intermédio dos quais os valores se manifestam. Entre os autores dessa corrente, o grande destaque no campo migratório, sem dúvida, é Stuart Hall (1932 - 2014).

Por fim, não poderíamos deixar de citar as contribuições de Bourdieu ${ }^{11-14}$, especialmente seus conceitos de capital cultural e espaço social. O primeiro pode ser visto, aqui, resumidamente, como uma ferramenta utilizada para analisar situações de classe na sociedade - de certa forma serve para caracterizar subculturas de classe ou de setores de classe. É tido como um recurso de poder que equivale e se destaca, especialmente, por ter como referência os recursos econômicos. Daí o termo capital associado ao termo cultura. Já espaço social é retratado por Bourdieu como um campo de lutas no qual os atores (indivíduos e grupos) elaboram estratégias que permitem manter ou melhorar sua posição social, a partir (e também) do capital cultural.

Segundo Erel, apesar de ter havido diversas teorizações de capital cultural em estudos de migração, uma característica predominante e comum tem sido o que o autor classifica como "abordagem mochila"15: parte do ponto de vista de que o sujeito, ao se deslocar, traz consigo um pacote de recursos culturais que podem ou não se encaixar na cultura do país de acolhida. Tal uso do conceito não é errado, porém, o autor argumenta que a migração resulta em novas formas de produção e reprodução do capital cultural e não pode ser vista simplesmente como espelhos de relações de poder, seja em relação ao país de origem, seja em relação ao país de destino. "Migrantes criam mecanismos de validação para o seu capital cultural, negociando simultaneamente com a maioria étnica, instituições e redes de migrantes"’5.

Assim, a partir da perspectiva intercultural, os estudos migratórios passam a revelar estruturas não-fixas de indivíduos e grupos em situação de deslocamento em territórios receptores, originários de diferentes tipos de sociedades (rural ou urbana, agrária ou industrial, central ou periférica etc.) com distintas tradições (hábitos, costumes), religiões e instituições políticas. Essas pessoas, frequentemente, falam outros idiomas e seguem diferentes práticas culturais e religiosas. Fisicamente, elas são diferentes, também, tanto na cor da pele, tipo do cabelo, estatura, traços do rosto etc., como no modo de se vestir, andar e se expressar. Algumas delas ficam concentradas e associadas a certos tipos de trabalho (geralmente de baixo status social) e vivem vidas segregadas em áreas residenciais afastadas ou restritas. Parte dessas estruturas, bem como a comunicação entre elas, é responsável pela geração de conflitos capazes de serem negociados ou não, mas, acima de tudo, pela construção da diversidade e identidade cultural do planeta, ou pela reconfiguração do conjunto de paisagens socioculturais da nossa época. "Os modos de organização e ação das comunidades diaspóricas incluídas em mais de um quadro social nacional estático, com referências culturais, territoriais e/ou linguísticas originais comuns entre eles através de redes sociais transnacionais (reais ou virtuais) veiculam discursos de solidariedade e/ou de identificação, além das fronteiras formais de seus respectivos países de 
acolhimento. É, portanto, um fenômeno 'pós-nacional' inerente à realidade social e política que caracteriza o mundo contemporâneo, marcado pelos movimentos migratórios em massa e a desigualdade, agora estrutural, entre nacionalestatal e cultural-identitário; onde diversidade cultural e a identidade, pertencimentos múltiplos e outras formações diaspóricas são majoritariamente a regra e não a exceção"16.

Nesse contexto, o interculturalismo passa a ser visto como um recurso simbólico - meio pelo qual damos sentido a práticas e relações sociais - para os estudos migratórios contemporâneos. O reconhecimento do 'outro' (alteridade) ${ }^{\mathrm{i}}$ possibilita que relações de contato e troca cultural se efetivem em grupos diferentes para que, justamente, esses possam se reelaborar, garantindo assim sua inserção em um mundo acelerado pela lógica da globalização.

Relações interculturais costumam ocorrer nos seguintes âmbitos de interação: 1) a comunicação entre dois membros de duas origens nacionais diferentes; 2) a comunicação entre o imigrante e a sociedade que o acolhe; 3) a comunicação intergrupal dentro da própria sociedade (gênero, idade, classe social etc.); e 4) a comunicação inter-racial e interétnica ${ }^{17}$.

Como todo conceito teórico, o interculturalismo não é completo e imutável, sendo passível de críticas. Uma delas é feita por Kern ${ }^{18}$ que, em uma revisão de literatura sobre o termo, aponta que, por trás do caráter aproximativo e positivo do conceito, trata-se de um argumento que vai se banalizando e não é tão neutro nem tão espontâneo como parece. Funcionaria como instrumento conceitual de disfarce ideológico para a reterritorialização capitalista e para o próprio processo de naturalização da exclusão do subalterno, ou ainda, de um sucedâneo para o aumento de consumo de determinados bens culturais, favorecendo a expansão capitalista pelo globo.

Outra crítica no mesmo sentido é colocada por Bhabha. Para o autor, o interculturalismo não oferece perspectivas profundas ou verdades. "É uma problemática de representação e individualização colonial que reverte os efeitos da recusa colonialista, de modo que outros saberes 'negados' se infiltrem no discurso dominante e tornem estranha a base de sua autoridade - suas regras de reconhecimento"19.

\section{A comunicação intercultural para além da ação instrumental}

O início e trajetória da Comunicação nos estudos migratórios interculturais se confundem com a própria criação e organização do campo como área do conhecimento humano. A Escola de Chicago (comentada anteriormente), considerada pioneira para o desenvolvimento da área, promoveu os primeiros estudos com uma visão do imigrante como ator social que interage simbolicamente com sua comunidade de ação (o território de destino entendido como 'laboratório social') por meio de estratégias comunicativas.

Assim, um dos primeiros trabalhos de que se tem notícia que une claramente a imigração à Comunicação é o livro The immigrant press and its control, de Robert Park, escrito em 1922. Contratado pelo governo dos Estados Unidos para pesquisar a mídia étnica no país, o autor - um dos grandes nomes da Escola de Chicago - estimou há quase cem anos que a tiragem total de jornais editados em línguas que não o inglês nos Estados Unidos atingia a casa dos dez milhões de exemplares. Segundo a pesquisa, a imprensa imigrante desta época tinha três características principais: 1) era uma experiência específica da primeira geração de imigrantes estrangeiros nos Estados Unidos; 2) tinha habilidade de orientar os imigrantes sobre a cultura local; e 3) servia de suporte para processos de assimilação ${ }^{\text {ii }}$.

\footnotetext{
i Por alteridade, utilizamos o conceito de Jodelet, para quem, a alteridade é um duplo processo de construção e de exclusão social, de indentidade e pluralidade que, indissoluvelmente ligados, mantêm a unidade por meio de um sistema de representações. "A noção de alteridade permanece demasiado genérica - até mesmo polissêmica (...). Acha-se situada no plano do vínculo social (...) pois não aparece como um atributo que pertenceria à essência do objeto visado, mas sim como uma qualificação que lhe é atribuída do exterior"20.

ii Outro estudo dessa época e que segue a mesma linha de Park, é The declining immigrant press, escrito por Marshall Beuick, em 1927. Nele, aqui resumidamente, o autor discorre sobre o fim deste tipo de periódico a partir do momento em que o imigrante 'aprende a navegar' no território de origem e passa a consumir a imprensa tradicional.
} 
A partir das décadas de 1940 e 1950, Miège ${ }^{21}$ e Balle ${ }^{22}$ falam sobre uma intensa produção acadêmica e profissional que abrange os processos comunicacionais, refletindo a efervescência das inovações das Tecnologias de Informação e Comunicação (TICs). Desse modo, o pensamento comunicacional aparece a partir de preposições teóricas de diversas disciplinas e atrelado às sociedades contemporâneas, uma vez que refletiria as dinâmicas dos meios, especialmente o rádio e a televisão.

Nos Estados Unidos, é desta época a chamada Escola de Palo Alto (ou Colégio Invisível), da Califórnia. Os autores dessa corrente são reconhecidos por diversificar o pensamento comunicacional, com estudos sobre a Comunicação em seus vários níveis de complexidade, contextos múltiplos e sistemas regulares. Com o lema de que 'é impossível não se comunicar', nota-se uma ênfase no papel do emissor e receptor. São desse período, por exemplo, os estudos The immigrant takes his stand: the Norwegian immigrant press and American public affairs, 1847 a 1872, publicado por Arlow W. Anderesen, em 1953, e Race and America's Immigrant Press - How the Slovaks were taught to think like white people, de Robert M. Zecker, escrito em 1962.

Na América Latina e Brasil, podemos dizer que a Comunicação começou a participar dos estudos migratórios com uma perspectiva intercultural a partir dos anos 1990, com as ideias de Jesus MartínBarbero, sobre a noção de mídia muito além do estudo de discursos midiáticos ou de estruturas de produção, mas como 'prática social', como propõe, aliás, a tradição dos Estudos Culturais latino-americanos, principalmente na linha do clássico De los medios a las mediaciones.

Com formação em Filosofia, Martín-Barbero trabalha o campo dos mass media, seus dispositivos de produção, seus rituais de consumo, seus aparatos tecnológicos, seus códigos de montagem, de percepção e reconhecimento. Segundo o autor, a Comunicação tornou-se uma questão de mediação e não de meios, uma questão de cultura e, portanto, não só de conhecimentos, mas de reconhecimentos, o que exige investigações a partir da articulação entre práticas comunicacionais e movimentos sociais (mediações e sujeitos). "Os processos políticos e sociais desses anos - regimes autoritários em quase toda América do Sul, cercados de lutas de libertação na América Central, emigrações imensas de homens, a política, a arte e a investigação social - destruíram velhas seguranças e abriram novas brechas para o enfrentamento da 'verdade cultural' desses países: à mestiçagem que não é só aquele feito racial do qual viemos, mas uma trama hoje de modernidade e descontinuidade cultural, de formações sociais e estruturas de sentimento, de memórias imaginárias que relacionam o indígena com o rural, o rural com o urbano, o folclórico com o popular e o popular com o massivo”²3.

Semelhante contribuição para os estudos migratórios dentro da Comunicação na América Latina vem do antropólogo Arjun Appadurai. O autor desenvolve o conceito de ethnoscape (ao lado de outros, como financescape, technoscape, mediascape e ideoscape) para explicar a mundialização a partir de uma teoria dos fluxos-paisagens como uma resposta aos modelos que estavam em curso até então para se pensar a globalização - muitos deles baseados na ideia de oposição entre centro e periferia e nas concepções neomarxistas do desenvolvimento.

De acordo com Abélès ${ }^{24}$, o conceito de ethnoscape introduzido por Appadurai é bastante difícil de traduzir. Scape remete à ideia de paisagem. "Os ethnoscapes são, em alguma medida, as paisagens que os grupos em movimento constituem com respeito às suas próprias origens e às vicissitudes que enfrentam”"24. No entanto, lembra o autor, a noção de paisagem é, por si só, ambígua: designa simultaneamente o exterior, o mundo tal qual ele nos aparece, mas nos remete igualmente à interioridade, à representação que trazemos conosco.

"Por ethnoscape, quero dizer a paisagem constituída por pessoas deslocadas no mundo em que vivemos: turistas, imigrantes, refugiados, exilados, os trabalhadores convidados, e outros grupos móveis e indivíduos constituem uma característica essencial do mundo que parece afetar a política de (e entre) as nações em um grau até então sem precedentes. Isso não quer dizer que há comunidades e redes de parentesco, amizade, trabalho e lazer relativamente estáveis, bem como de nascimento, residência, e outras formas de filiação. Mas é dizer que o conjunto dessas estabilidades 
está em todos os lugares envolto com a trama do movimento humano, à medida que mais pessoas e grupos lidam com as realidades de ter que mover ou as fantasias de querer mover" 25.

A partir da dimensão comunicacional não apenas na sua acepção instrumental de veiculação, transmissão e/ou representação, mas principalmente, em suas conotações de vinculação social, interação simbólica e produção subjetiva - conjugada à teoria dos fluxos materiais, humanos, midiáticos, subjetivos e simbólicos - é que surge o conceito de comunicação intercultural.

Considerado um campo de estudo recente, o termo comunicação intercultural foi utilizado pela primeira vez por Edward T. Hall, em 1959, em seu trabalho na formação de diplomatas norte-americanos enviados ao exterior por meio da Foreign Service Institute (FSI), uma instância do governo dos Estados Unidos ${ }^{26,27}$. Com o objetivo de promover a comunicação entre esses portadores de diferentes culturas, Hall teria se interessado pelas dimensões ocultas da cultura e do papel tempo e espaço nesse processo.

Até mesmo por conta desse início formal e institucional, a comunicação intercultural se desenvolveu bastante dentro de uma perspectiva da comunicação organizacional e institucional, como um modelo de gestão da comunicação e diversidade em empresas, governos e instituições com relações transnacionais. Na verdade, é vista como um recurso para se estabelecer diálogos em um contexto global a fim de facilitar a compreensão mútua, estimular as relações de confiança e contribuir para as trocas em dimensões comerciais e políticas. Nesse sentido, são conhecidos no Brasil os estudos compilados na coletânea "Comunicação, interculturalidade e organizações: faces e dimensões da contemporaneidade" ${ }^{28}$.

Porém, o que gostaríamos de destacar é o desenvolvimento de pesquisas em comunicação intercultural que demonstram a pertinência desse campo para se analisar questões da comunicação relacionadas à migração e às trocas socioculturais. Nesse caso, verifica-se um interesse pelas vozes consideradas como minoritárias na conquista de mais espaço para tratar das problemáticas de identidade, cidadania e fronteiras. No Brasil, são importantes para essa vertente os estudos de ElHajji ${ }^{29-31}$, Cogo ${ }^{32-34}$, Brignol ${ }^{35}$, Zanfor$\operatorname{lin}^{36-37}$, entre outros. De maneira geral, esses autores vêm discutindo a distinção e natureza dos contextos de produção comunicacional dos imigrantes que surgem a partir das TICs e/ou de iniciativas próprias do sujeito imigrante ou de ações mediadas (por entidades confessionais, OSCs, coletivos, redes etc.) formais ou informais, colaborando para o entendimento dos modos de organização e produção dessas práticas, de formação de uma cidadania comunicativa, bem como, no contexto acadêmico, para a perspectiva de intercâmbio de conhecimento.

Essa perspectiva da comunicação intercultural é bastante alinhada com os conceitos mais amplos de comunicação alternativa, popular e comunitária. Em estudos anteriores ${ }^{38-40}$, procuramos demonstrar como ações práticas de comunicação feitas 'de' e 'para' imigrantes podem ter caráter mobilizador coletivo e de reconhecimento identitário visando, muitas vezes, a transformação da realidade social.

Segundo Peruzzo, são várias as denominações para esse tipo de comunicação, cada uma com suas especificidades: alternativa, participativa, participatória, horizontal, comunitária, dialógica e radical, dependendo do lugar, do tipo de prática e da percepção dos estudiosos. "Porém, o sentido político é o mesmo, ou seja, o fato de tratar-se de uma forma de expressão de segmentos empobrecidos da população, mas em processo de mobilização visando suprir suas necessidades de sobrevivência e de participação com vistas a estabelecer a justiça social"41.

Tais práticas comunicacionais englobam os meios tecnológicos e outras modalidades de canais de expressão que costumam colocar o grupo envolvido na posição de protagonista e de contra-hegemonia perante não só os veículos tradicionais de comunicação, mas à sociedade como um todo. Envolvem uma dinâmica de organização na produção de conteúdo que dá visibilidade e voz ao grupo envolvido - ao contemplar diversos tipos de informação - tornando-as um processo democrático e educativo, fortalecendo vínculos sociais, reciprocidade de interesses, cooperação e sentimento de pertença. Por meio delas, “[...] em última instância, realiza-se o direito de comunicar ao garantir o acesso aos canais de comunicação. Trata-se não apenas 
do direito do cidadão à informação, enquanto receptor - tão presente quando se fala em grande mídia -, mas do direito ao acesso aos meios de comunicação na condição de produtor e difusor de conteúdos" ${ }^{\prime 1}$.

No que se refere especificamente à questão da saúde, as implicações descritas dialogam com o item "Mediação"42, da Carta de Ottawa (1986), resumidamente, um documento elaborado durante a Primeira Conferência Internacional sobre Promoção da Saúde, realizada no Canadá, que buscou contribuir com as políticas de saúde em todos os países, de forma equilibrada e universal. Diz o documento: "Os pré-requisitos e perspectivas para a saúde não são assegurados somente pelo setor saúde. Mais importante, a promoção da saúde demanda uma ação coordenada entre todas as partes envolvidas: governo, setor saúde e outros setores sociais e econômicos, organizações voluntárias e não-governamentais, autoridades locais, indústria e mídia. As pessoas, em todas as esferas da vida, devem envolver-se neste processo como indivíduos, famílias e comunidades. Os profissionais e grupos sociais, assim como o pessoal de saúde, têm a responsabilidade maior na mediação entre os diferentes, em relação à saúde, existentes na sociedade" ${ }^{2}$.

\section{O caso da equipe de Base Warmis na discussão do 'Projeto pró-cesárea no SUS'}

"Somos mulheres voluntárias, que queremos transformar nossa realidade e melhorar as condições nas quais vivemos, desenvolvendo e promovendo atividades em nossas comunidades" 33 . Assim se autodefine a Equipe de Base Warmis - Convergências das Culturas, de São Paulo. O grupo faz parte do Organismo Internacional Convergência das Culturas, que tem por missão facilitar e estimular o diálogo entre as culturas, lutar contra violência e discriminação, promover os Direitos Humanos etc. Com uma intensa agenda de atividades realizadas em diversos espaços da cidade - entre eles o Centro Cultural São Paulo ${ }^{i i i}$ - reúne principalmente mulheres de origem sul-americanas em torno de diversas causas: culturais, migratórias, feministas, educacionais, laborais etc.

Como uma das formas de articulação, o grupo conta com um site oficial, um blog e páginas nas redes sociais, como Facebook, Twitter, Instagram e YouTube. Nesses espaços, costuma publicar conteúdos próprios, elaborados a partir das vivências de suas integrantes, mas também compartilha e replica material postado em outros veículos (reportagens da mídia tradicional, de organizações parceiras ou não, de veículos especializados na questão migratória etc.).

Em 2014, o grupo lançou a campanha 'No a La Violencia en el parto', em um evento realizado na Praça da Kantutaiv, com a participação, na ocasião, da Defensoria do Estado de São Paulo, da Coordenação de Políticas para Imigrantes da Prefeitura de São Paulo, de ONGs e grupos culturais. A justificativa foi: "No Brasil, uma de cada quatro mulheres relata que foi vítima de violência obstétrica e as mulheres imigrantes não estão a salvo de este tipo de violência. Somos imigrantes, mães e voluntárias. Somos testemunhas diárias da discriminação por nossa cor, nossa aparência, nosso sotaque, nossos costumes. E no momento do parto isso é mais grave porque muitas vezes as enfermeiras e os médicos têm preconceitos e não nos entendem e nos tratam mal. Queremos que esse maltrato pare, queremos ser respeitadas e tratadas com igualdade, queremos que o Brasil saiba o que estamos passando, e para isso temos que denunciar. [...] As mulheres imigrantes da cidade de São Paulo [...], muitas grávidas não fazem o Pré-natal e nenhum acompanhamento médico por medo de ser discriminada ou maltratada, colocando assim em risco sua saúde e a de seus bebês. Outro problema é que a maior parte das mulheres imigrantes preferem um parto normal por ser parte de sua cultura, só que na maioria dos casos não conseguem, assim, o que deveria ser uma experiência

iii Inaugurado em 1982, o Centro Cultural São Paulo é uma instituição pública subordinada à Secretaria Municipal de Cultura da cidade de São Paulo. Reúne um conjunto de bibliotecas multidisciplinares, pinacoteca (com coleções de acervos da cidade), jardins, espaços de estudo e convivência, além de promover diversas atividades artísticas e culturais. Está localizado na Rua Vergueiro, 1000, no bairro do Paraíso, em São Paulo.

iv Trata-se de uma praça pública, no bairro do Pari, em São Paulo, onde, semanalmente há a Feira da Kantuta, formada por imigrantes bolivianos, majoritariamente, que vendem produtos típicos de seu país (comida, artesanato etc.) e fazem apresentações de música e dança folclórica. 
maravilhosa passa a ser dolorosa e triste por sentirem-se maltratadas e impotentes sem poder fazer nada a respeito"44 (Tradução nossa).

Diante desse posicionamento, a Equipe de Base Warmis participou ativamente dos debates sobre o que ficou conhecido como 'Projeto pró-cesárea no SUS' ou 'PL 435/2019'. Em junho de 2019, a deputada estadual Janaína Paschoal (PSL) apresentou um projeto de lei à Assembleia Legislativa do Estado de São Paulo (ALESP) prevendo a garantia às gestantes do Sistema Único de Saúde (SUS) a opção pelo parto cirúrgico (cesárea) a partir da $39^{\mathrm{a}}$ semana de gestação, sem a necessidade de indicação clínica para o procedimento. Não só por conta do caráter de urgência colocado pela parlamentar - o que desobrigava a análise do mérito pelas comissões da saúde e da mulher, como indicam as normas do Legislativo -, mas também pelo mérito do projeto, o assunto virou polêmica, repercutindo por vários dias nos veículos de comunicação e ganhando o debate nas redes sociais.

Tal participação da Equipe de Base Warmis no debate público do assunto deu-se presencialmente com suas integrantes se reunindo internamente e presencialmente na ALESP, acompanhando sessões abertas, protestos, articulando com outros movimentos, bem como produzindo e compartilhando conteúdo em suas redes sociais, em espanhol e português. Análise de conteúdo feita durante todo o mês de junho de 2019 justamente o período em que o assunto do 'Projeto pró-cesárea no SUS' surgiu e repercutiu - mostrou que o grupo publicou no Facebook ${ }^{21}$ posts sobre o assunto.

A origem (fonte) e o formato desse conteúdo são os mais variados possíveis, porém, todos se posicionam contra o projeto de lei. Há desde cartazes chamando os usuários da página para rodas de conversa e/ou audiência pública, infográficos sobre dados referentes à cesárea no Brasil, a matérias publicadas sobre o assunto por veículos comerciais tradicionais (Folha de S.Paulo, BBC Brasil, G1 etc.) e fotos das integrantes do grupo participando das ações. Alguns exemplos:

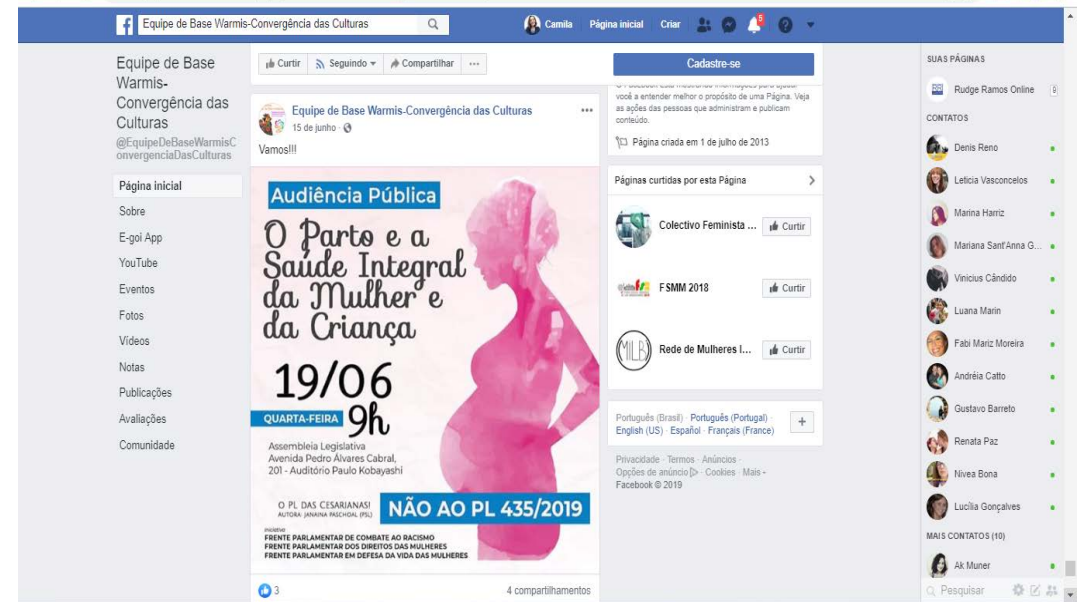

Figura 1 - Audiência pública: O parto e a saúde integral da mulher e da criança Fonte: Página Equipe de Base Warmis-Convergência das Culturas (2019)vi.

\footnotetext{
v Concentramo-nos aqui nas postagens da página oficial do Facebook da Equipe Base-Warmis, uma vez que apenas foram replicadas e/ou redirecionadas para Twitter e Instagram. No caso de vídeos, constam também no YouTube. O blog do grupo estava desatualizado no momento da pesquisa (a última postagem havia sido em fevereiro de 2019), e o site contém mais um conteúdo estático, ou seja, que não é atualizado constantemente, como Quem Somos, Projetos, Materiais e Contato. 


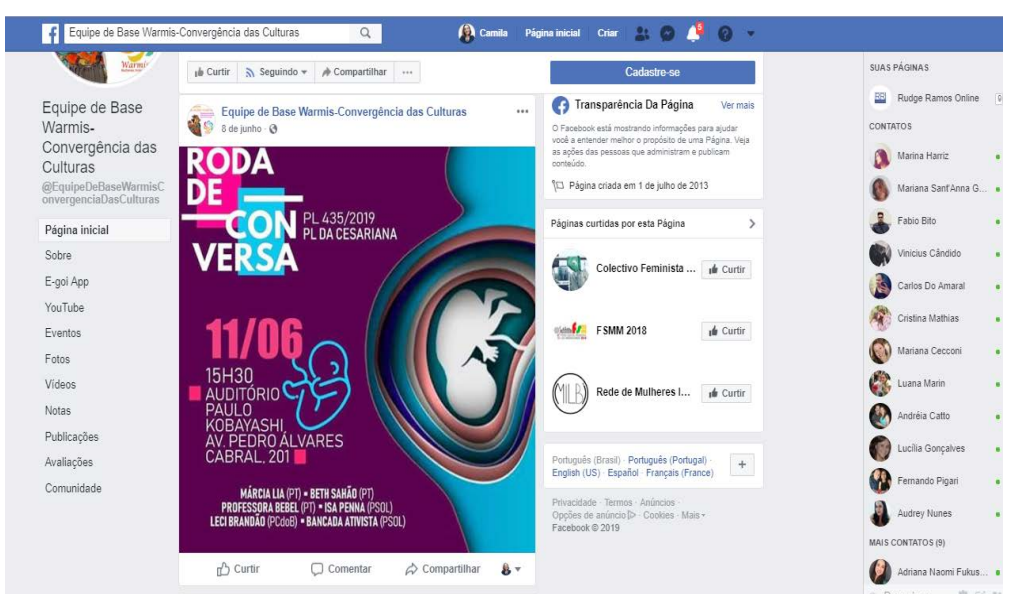

Figura 2 - Roda de conversa: PL 435/2019 PL da cesariana

Fonte: Página Equipe de Base Warmis-Convergência das Culturas (2019)vii.

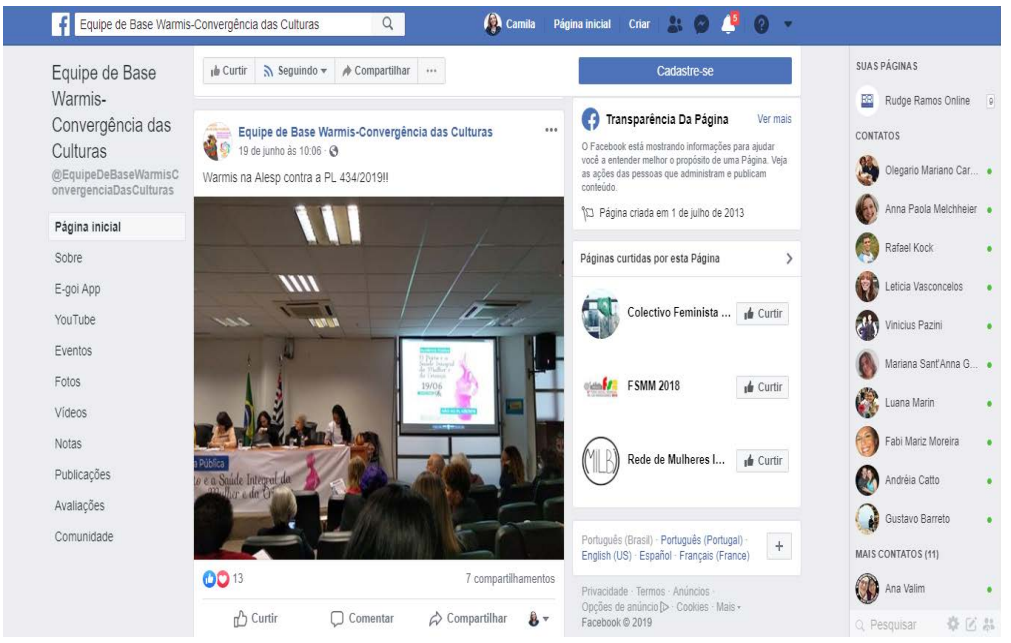

Figura 3 - Warmis na Alesp contra a PL 434/2019!

Fonte: Página Equipe de Base Warmis-Convergência das Culturas (2019) viii.

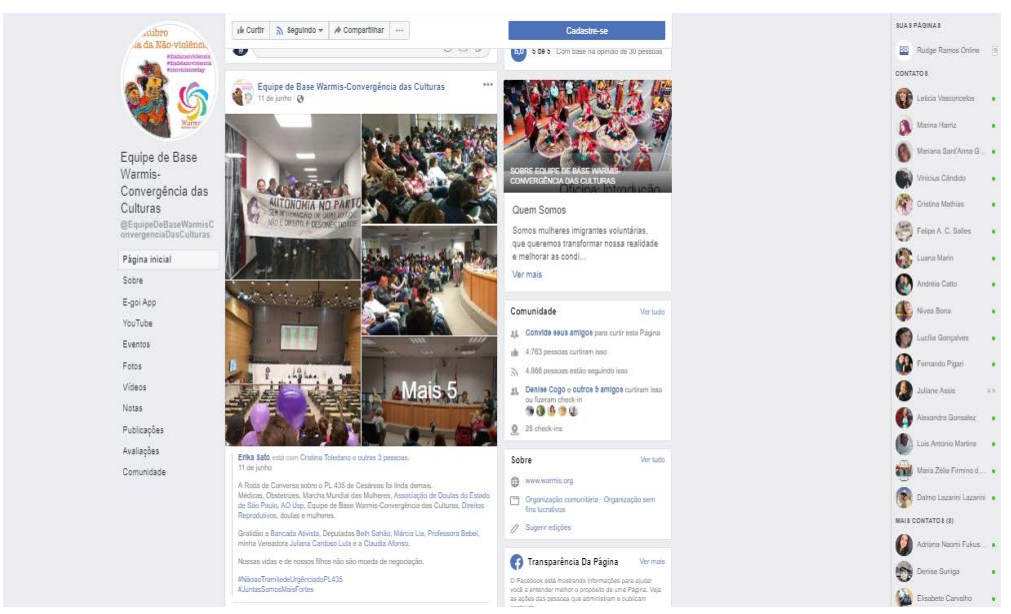

Figura 4 - Roda de Conversa sobre o PL 435 de Cesáreas

Fonte: Página Equipe de Base Warmis-Convergência das Culturas (2019)ix.

\footnotetext{
vii Disponível em: https://bit.ly/34pKkvZ. Acesso em: 26 nov. 2019.

viii Disponível em: https://bit.ly/2QUJ93N. Acesso em: 27 nov. 2019

ix Disponível em: https://bit.ly/2Di8v3w. Acesso em: 27 nov. 2019.
} 


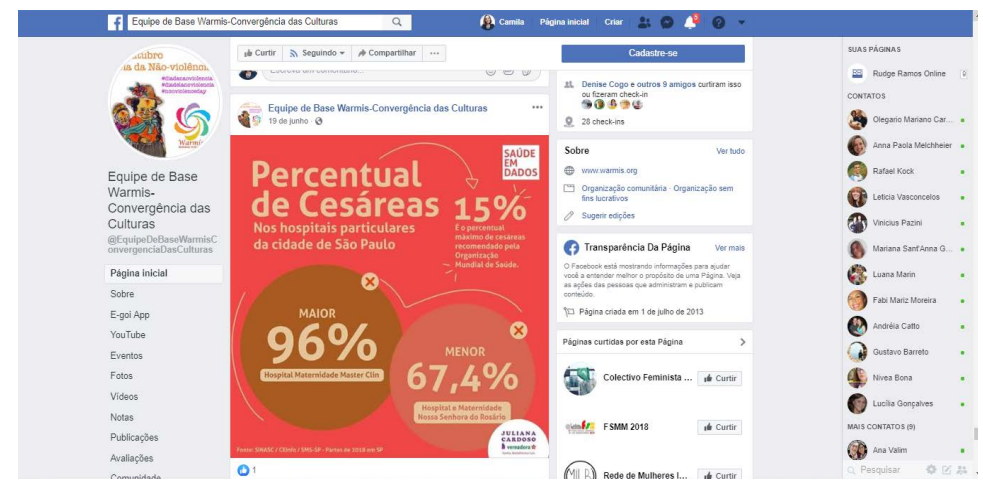

Figura 5 - Percentual de cesáreas nos hospitais da cidade de São Paulo Fonte: Página Equipe de Base Warmis-Convergência das Culturas (2019).

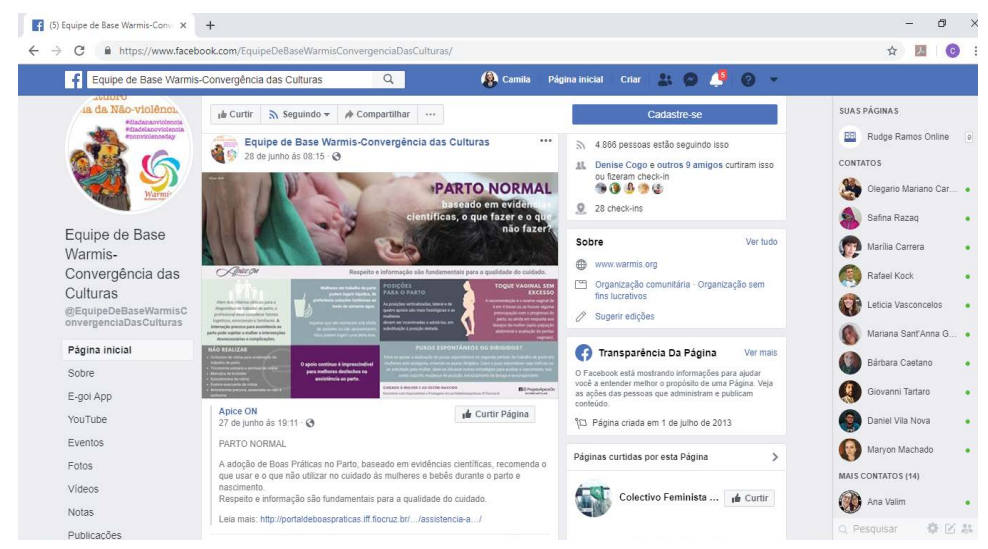

Figura 6 - Parto normal baseado em evidências científicas, o que fazer e o que não fazer? Fonte: Página Equipe de Base Warmis-Convergência das Culturas (2019)

Além disso, há dois vídeos: um intitulado 'PL do Parto Humanizado’xii produzido pela Rede Humanista de Notícia em Saúde (REHNO), sobre os riscos da cesárea para a saúde da mulher e do bebê; e outro com uma explicação da pediatra, epidemologista e coordenadora geral da Sentidos do Nascer, Sonia Lansky, sobre o que ela classifica de 'epidemia de cesáreas e de bebês prematuros no Brasil' ’iii.

Chama a atenção ainda um post compartilhado no período, alertando para a fake news ${ }^{\mathrm{xiv}}$ : 'Programa Parto Adequado, da Associação Nacional de Saúde (ANS), não é \#PLdaMorteMaterna'. O texto tem o objetivo de esclarecer que o programa não promove cesáreas, mas foi criado para "controlar a epidemia de cesáreas no sistema suplementar”45 e tem como uma das regras aumentar o número de partos vaginais como "experiência positiva e segura para as mulheres e os bebês"45. Além disso, diz que, pelo Programa, a gestante que pedir por uma cesárea, por iniciativa própria, "receberá atendimento psicológico e multidisciplinar"45. O texto termina com uma solicitação para que essa informação seja circulada: "Não se deixe enganar por mentiras!! Envie para suas amigas usuárias do SUS e coloque nas redes!"45.

\footnotetext{
x Disponível em: https://bit.ly/2DrGqXr. Acesso em: 27 nov. 2019.

xi Disponível em: https://bit.ly/33uJz3H. Acesso em: 27 nov. 2019.

xii Disponível em: https://www.facebook.com/quatrov/videos/1092728704265763/?t=4. Acesso em: 28 nov. 2019

xiii Disponível em: https://www.youtube.com/watch?v=jExvKk7NPxY. Acesso em: 28 nov. 2019

xiv Termo utilizado popularmente para designar notícias falsas divulgadas, atualmente, principalmente nas redes sociais.
} 


\section{Estrutura contra-hegemônica, polifônica e novas formas de linguagem}

Antes de entrarmos na análise do conteúdo descrito no item anterior, ressaltamos que, para fins de comparação do conteúdo veiculado pela Equipe de Base Warmis sobre o ‘Projeto pró-cesárea no SUS’ ou 'PL 435/2019' e outras práticas comunicacionais tradicionais, fizemos também uma análise de conteúdo, de abordagem qualitativa, das matérias veiculadas sobre o tema na mídia tradicional comercial, representada aqui pelos veículos: portais Folha de S.Paulo, Globo.com, além das revistas semanais Veja, Isto É e Época. No total, foram 10 matérias jornalísticas (reportagens) publicadas sobre o assunto no mesmo período, em junho de 2019, sendo que uma delas (a de Veja) foi uma entrevista no formato ping-pong ${ }^{\mathrm{xv}}$ com a deputada autora do projeto. Com exceção dessa última, disponível também em vídeo no site da revista, todas elas foram produzidas no formato texto, sendo algumas ilustradas ainda com fotografias (da Janaína Paschoal, da Alesp ou de bebês) e/ou infográficos (dados estatísticos e ilustrações de procedimentos de parto, natural ou cesárea). De maneira geral, todas apresentaram:

1. Diversos dados estatísticos sobre o assunto, entre eles: mostram que o Brasil é o segundo país do mundo com a maior taxa de cesáreas (55,5\%), atrás apenas da República Dominicana (58,1\%); que dos partos feitos no SUS, 40\% ocorrem por meio de cesarianas (enquanto que na rede privada, o índice chega a 84\%); e que o Estado de São Paulo registra o maior número de mortalidade materna (foram 60,6 mortes por 100 mil em 2018).

2. Entrevistas com a deputada Janaína Paschoal, autora do projeto, que defende a proposta argumentando que "há milhares de mulheres do SUS que passam por situações de violência obstétrica e são impedidas tanto de exercer seu direito de escolha em relação a uma cesariana como ao uso de analgesia quando o parto ocorre por via vaginal" 46 .

3. Posicionamento da Secretaria da Saúde do Estado de São Paulo sobre a possibilidade da rede de saúde paulista ter condições de absorver um eventual aumento de cesáreas.

4. Informações da Organização Mundial da Saúde (OMS), que considera que a taxa ideal de cesáreas em um país seja entre 10\% a 15\% dos partos e recomenda a cirurgia apenas por razões médicas.

5. Explicações sobre o que é uma cesariana, que se trata de uma intervenção cirúrgica que ajuda a salvar vidas, como nos casos em que a placenta está obstruindo a saída do bebê do útero, mas está associada a um maior número de partos prematuros entre outros fatores.

6. As opiniões de médicos especialistas no assunto, obstetras e pediatras, principalmente, (a maioria criticando o projeto), bem como o posicionamento de órgãos associativos como a Sociedade de Obstetrícia e Ginecologia ou o Conselho Regional de Medicina do Estado de São Paulo. A Folha de S.Paulo chega a publicar uma coluna de opinião, na qual o autor - o jornalista Hélio Schwartsman questiona se a cesariana é um direito da mulher ou um crime contra a saúde pública.

7. A cobertura dos debates, audiência pública e reuniões na ALESP, com entrevistas com deputados da oposição e da situação.

Também fizemos uma análise de conteúdo ${ }^{\mathrm{xvi}}$, no mesmo período, das notas e comunicados oficiais de instituições formais de classe profissional que estão, de alguma maneira, envolvidas com a temática e se

\footnotetext{
xV É um termo jornalístico usado para identificar texto escrito em formato de pergunta e resposta que retrata unicamente a conversa entre o jornalista e o entrevistado.

xvi Todas as análises de conteúdo elaboradas para este artigo foram feitas seguindo as recomendações de Bardin (tradução nossa) ${ }^{1}$, no que diz respeito aos "pólos cronológicos": a) Pré-análise; b) Exploração do material; e c) Tratamento dos resultados,

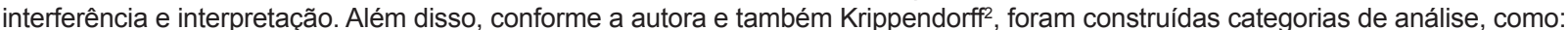
posicionamento (a favor ou contra o projeto de lei), personagens, formato, recursos etc. No total, foram analisados 35 registros.
} 
pronunciaram a respeito da questão. Esse material foi publicado nos sites e redes sociais dessas organizações. Como principais resultados, destacamos:

1. Associação de Obstetrícia e Ginecologia do Estado de São Paulo (SOGESP): se posicionou contra o projeto, afirmou que a proposta foi baseada em "impressões pessoais" ${ }^{47}$ da deputada (e não em estudo científico ou estatísticas) e pediu a retirada do projeto da pauta de votação e do regime de urgência.

2. Sindicato dos Psicólogos do Estado de São Paulo (SinPsi): mostrou "firme oposição ao projeto" ${ }^{\text {, }}$, argumentando que desrespeita 56 recomendações da OMS e pede um debate amplo com a sociedade civil.

3. Conselho Regional de Medicina do Estado de São Paulo (CREMESP): não citou o projeto especificamente, mas divulgou uma nota no período se opondo "à vilanização da prática cirúrgica obstétrica consagrada pela ciência"49. Diz o texto que: "repudia discursos de ódio contra a categoria médica, que tentam taxar esses profissionais de mercantilistas quando, na verdade, o que se percebe é que o interesse econômico está do lado de quem acusa: em querer, com falsa ciência e com discursos ideológicos, demonizar rotinas médicas seguras e consagradas na assistência médica obstétrica" ${ }^{\circ}$.

4. Ordem dos Advogados do Brasil - Seção São Paulo (OAB). Assinada em conjunto pelas comissões de Direitos Humanos, da Mulher Advogada, da Igualdade Racial e da Diversidade Sexual, a nota recomenda a rejeição do projeto, destacando aspectos legais, entre eles: não atende às disposições do artigo 219 da Constituição do Estado de São Paulo, bem como, do artigo 196, da Constituição Federal, além de ferir o princípio constitucional da economicidade que deve nortear todos os atos da Administração Pública e diz que o tema já está disciplinado pela Lei Estadual 15.759/15, que exaustivamente dispõe sobre o parto humanizado e expressamente sobre a oportunidade de escolha dos métodos natais por parte da parturiente.

A partir disso, verifica-se que a comunicação veiculada pela Equipe de Base Warmis sobre o 'Projeto prócesárea no SUS' ou 'PL 435/2019' trouxe para o debate público a mulher imigrante, até então invisível, seja pela cobertura da mídia comercial tradicional ou pela comunicação oficial de instituições formais de classe profissional envolvidas com a temática (como revelou a análise de conteúdo realizada). Trata-se de um ator social importante para a questão, não só pela sua identidade de imigrante - que conforme mostrado enfrenta mais dificuldades com o atendimento na rede de saúde que o cidadão nacional (preconceito, dificuldades com o idioma ou mesmo questões de ordem cultural) - mas, principalmente, por sua identidade de mulher - a principal 'vítima' de toda a discussão.

Ao se posicionar publicamente contra o projeto de lei apresentado e mobilizar sua rede de comunicação, enfatizando a participação, a luta, o diálogo e as diferenças culturais, são revelados pelo grupo diversos esquemas possíveis que podem compor uma força contra-hegemônica via campo da comunicação. Destaca-se que estamos falando aqui de uma disposição coletiva sociocultural que está em constante processo de inter-relações e, ainda que menor em comparação ao sistema dominante (estrutura e alcance, principalmente), não deixa de participar na disputa por direitos e cidadania.

Entre esses esquemas possíveis, revela-se, em um primeiro momento, sua estrutura polifônica, na qual a pluralidade de vozes é uma realidade. No conteúdo publicado pela Equipe Base Warmis, a partir de outras visões, fontes e contextos, mas que, de alguma maneira, dialogam com o universo envolvido dessas mulheres imigrantes, percebe-se o interesse pelo outro (alteridade), pela negociação, pela democratização de forças e redução de visões preconceituosas e preconcebidas.

Do mesmo modo, verifica-se, na prática de comunicação retratada neste trabalho, a possibilidade de vozes consideradas como minoritárias conquistarem mais espaço para tratar das problemáticas de identidade, cidadania e fronteiras. Em sua dimensão comunicacional, mediada pelas TICs, a interculturalidade aparece 
aqui como uma alternativa de organização social não utópica - no sentido de uma convivência plena de todas as formas de vida -, mas, que supõe uma interação tensa, porém, controlada, na qual o conflito é natural, mas, negociado, favorecendo trocas recíprocas e novas composições de sociabilidade. São as identidades, especificidades e lógicas internas que devem ser reconhecidas na diferença.

Em um segundo momento, outro ponto desse esquema possível de comunicação que se revela são as novas formas de linguagem, que acabam por favorecer uma estrutura mais integrada entre produtor e receptor do conteúdo. Uma simples fotografia selfie tirada durante o protesto da Alesp contra o projeto, com um equipamento não profissional (um mero celular), já se transforma em um conteúdo formal de comunicação para aquele grupo, indicando que as pautas, as decisões sobre o que publicar ou não e as formas de abordagem são descentralizadas e uma constante alimentadora de todo o processo.

Soma-se a isso a perspectiva da Educação e o sentido maior de 'informar', 'esclarecer' e 'conscientizar' o grupo envolvido sobre os riscos da cesárea para as mulheres e os bebês. Pela perspectiva da comunicação para o desenvolvimento, as práticas midiáticas têm como função educar, porém, isso entre os veículos comerciais tradicionais e outros acaba se perdendo em meio a interesses econômicos e políticos. A postagem citada anteriormente alertando para a fake news é um indicativo não só dessa função educativa com relação à temática abordada - o fato de dizerem que o 'Programa Parto Adequado', da ANS, era a mesma coisa que a '\#PLdaMorteMaterna' - mas um recurso que favorece o consumo crítico das mensagens midiáticas.

\section{Considerações finais}

Neste artigo, procuramos demonstrar, de maneira interdisciplinar unindo estudos migratórios, comunicação e saúde, de que forma a comunicação intercultural no caso de processos migratórios pode contribuir para questões como direitos de cidadania, reconhecimento identitário e integração sociocultural a partir de uma questão de saúde pública.

Para isso, nos utilizamos da análise de um exemplo concreto que foi a atuação, no âmbito da comunicação, da Equipe Base Warmis - Convergência de Cultura no debate sobre o 'Projeto pró-cesárea no SUS' ou 'PL 435/2019', apresentado pela deputada estadual Janaína Paschoal, prevendo a garantia às gestantes do SUS a opção pelo parto cirúrgico (cesárea) a partir da $39^{\text {a }}$ semana de gestação, sem a necessidade de indicação clínica para o procedimento, ocorrido no Estado de São Paulo, em junho de 2019.

Partindo de uma breve revisão de literatura do termo interculturalidade, chegamos ao conceito de comunicação intercultural, entendida não somente a partir de seu alcance instrumental, de veiculação, transmissão e/ou representação, mas principalmente, em seu sentido de vinculação sociocultural, interação simbólica e produção subjetiva.

Além disso, enfatizamos sua importância no contexto de produção comunicacional dos imigrantes que surgem a partir das TICs, em uma tentativa de colaborar para o entendimento dos modos de organização e produção dessas práticas que, assim como a perspectiva da comunicação alternativa, popular e comunitária vem demonstrando, podem ter caráter mobilizador coletivo e de reconhecimento identitário visando, muitas vezes, a transformação da realidade social, ainda que essa signifique uma coexistência sociocultural, porém negociada.

\section{Referências}

1. $\quad$ Bardin L. Análise de conteúdo. Lisboa: Edições 70; 1977.

2. Krippendorff K. Metodologia de analisis de contenido. Barcelona: Ediciones Paidós; 1990.

3. Faist T. Transnationalization and development. Toward an alternative agenda. In: Schiller NG, Faist T, editors. Vol. 12, Migration, development and transnationalization. A critical stance. New York: Berhahn Books; 2010. p. 63-99. 
4. $\quad$ Cogo D. Comunicação e diversidade: cenários e possibilidades da comunicação intercultural em contextos organizacionais. In: Moura CP, Ferrari MA, organizadores. Comunicação, interculturalidade e organizações: faces e dimensões da contemporaneidade. Porto Alegre: EDIPUCRS; 2015. p. 96-116.

5. $\quad$ Canclini NG. Diferentes, desiguais e desconectados. Rio de Janeiro: Editora UFRJ; 2005.

6. Canclini NG. Culturas híbridas: estratégias para entrar e sair da modernidade. São Paulo: Edusp; 1998.

7. Canclini NG. Cultura sem fronteira [entrevista]. Cad Leit [Internet]. 2007 [citado em 2019 jul. 15]; Entrevista por Reynaldo Damazio.

8. Simmel G. O estrangeiro. RBSE [Internet]. 2005 dez [citado em 2019 jul. 15];4(12): 265-271. Disponível em: https://bit.ly/34qOow4.

9. Schütz A. O estrangeiro: um ensaio em Psicologia Social. R Espaço Acad [Internet]. 2010 [citado em 2019 jul. 22];10(113):117-129. Disponível em: https://bit.ly/33thFol.

10. Borket M, Martín Pérez A, Scott S, De Tona C. Introduction: understanding migration research (across national and academic boundaries) in Europe. FQS [Internet]. 2006 maio [citado em 2019 jul. 15];7(3). Disponível em: https://bit.ly/20o2ed4.

11. Bourdieu P. Questões de sociologia. Rio de Janeiro: Marco Zero; 1983.

12. Bourdieu P. The forms of capital. In: Richardson JG, editor. Handbook of theory and research for the sociology of education. New York: Greenwordpress; 1986. p. 241-259.

13. Bourdieu P. Espaço social e poder simbólico [Internet] [Tradução da conferência pronunciada na Universidade de San Diego, em março de 1986]. Disponível em: https://edisciplinas.usp.br/pluginfile.php/3935267/mod resource/content/1/Espa\%C3\%A70\%20social\%20e\%20poder\%20simb\%C3\%B3lico.pdf.

14. Bourdieu P. O poder simbólico. Lisboa: Difel; 1989.

15. Erel U. Migrating cultural capital: Bourdieu in migration studies. Sociology. 2010;4(4):642-60.

16. ElHajji M. La diaspora maghrébine à Montréal face aux aléas de I interculturel: le rôle des médias locaux, transnationaux et communautaires. R Româna Comunic Rel Pub. 2012;14:85-100.

17. Israel E. Comunicación intercultural i construcción periodística de la deferència. Anàlisi. 1995; 18:59-85.

18. Kern D. O conceito de hibridismo ontem e hoje: ruptura e contato. Métis Hist Cult. 2004;3(6): 53-10.

19. Bhabha H. O local da cultura. Belo Horizonte: Editora UFMG; 1998.

20. Jodelet D. A alteridade como produto e processo psicossocial. In: Arruda A, organizador. Representando a alteridade. Petrópolis: Vozes; 2002. p. 47-68.

21. Miège B. O pensamento comunicacional. Petrópolis: Vozes; 2000.

22. Balle F. Comunicación y sociedad: evolución y análisis comparativo de los medios. Santa Fé de Bogotá: Tercer Mundo Editores; 1994.

23. Martín-Barbero J. De los medios a las mediaciones: comunicación, cultura e hegemonía. México: Editorial Gustavo Gilli; 1991.

24. Abélès M. Avant-propos. In: Appadurai A. Après le colonialisme: les conséquences culturelles de la globalisation. Damasceno MM, tradutor. Paris: Payot; 2005.

25. Appadurai, A. Modernity at Large - Cultural Dimensins of Globalization. Minneapolis: University Minnesota Press; 1996.

26. ElHajji M. Nosso norte é o sul: como pode a pesquisa em comunicação intercultural poscolonizar-se? Rio de Janeiro; 2019. [Comunicação informal].

27. Ferrari MA. Comunicação intercultural: perspectivas, dilemas e desafios. In: Moura CP, Ferrari MA, organizadores. Comunicação, interculturalidade e organizações: faces e dimensões da contemporaneidade. Porto Alegre: EDIPUCRS; 2015. p. 43-64.

28. Moura $\mathrm{CP}$, Ferrari MA, organizadores. Comunicação, interculturalidade e organizações: faces e dimensões da contemporaneidade. Porto Alegre: EDIPUCRS; 2015. 
29. ElHajji M. Comunicação intercultural: prática social, significado político e abordagem científica. E-COMPÓS [Internet]; 2006 ago. [citado em 2019 jul. 11];6:2-16. Disponível em: http://www.e-compos. org.br/e-compos/article/download/86/86/.

30. ElHajji M. Mapas subjetivos de um mundo em movimento: migrações, mídia étnica e identidade transnacionais. Rev Eptic [Internet]. 2011 maio-ago. [citado em 2019 jul. 11];13(2). Disponível em: https://seer.ufs.br/index.php/eptic/article/view/109/94.

31. ElHajji M. La diaspora maghrébine à Montréal face aux aléas de I interculturel: le rôle des médias locaux, transnationaux et communautaires. R Româna Comunic Rel Pub. 2012;14:85-100.

32. Cogo D. Cidadania comunicativa das migrações transnacionais: usos de mídias e mobilização social de latino-americanos. In: Cogo D, ElHajji M, Huertas A, editores. Diásporas, migrações, tecnologias da comunicação e identidades transnacionais. Belaterra: Instut de la Comunicació de la Universitat Autònoma de Barcelona; 2012. p. 43-66.

33. Cogo D, Badet M. Guia das migrações transnacionais e diversidade cultural para comunicadores. Bellaterra: Instuto Humaitas Unisinos; Instituo de la Comunicación de la UAB; 2013.

34. Cogo D. Haitianos no Brasil: comunicação e interação em redes migratórias transnacionais. Chasqui [Internet]. 2014 mar. [citado em 2019 jul. 22];125:23-22. Disponível em: https://revistachasqui.org/ index.php/chasqui/article/view/39/51.

35. Brignol LD. Migrações transnacionais e usos sociais da Internet: identidade e cidadania na diáspora latino-americana [tese]. São Leopoldo: Universidade do Vale do Rio dos Sinos; 2010.

36. Zanforlin SC. Etnicidade, migração e comunicação: etnopaisagens transculturais e negociações de pertencimento [tese]. Rio de Janeiro: Universidade Federal do Rio de Janeiro; 2011.

37. Zanforlin SC. Etnopaisagens, migração contemporânea e as tecnologias da comunicação: o corredor da central e a nova migração africana para o Rio de Janeiro. In: Cogo D, ElHajji M, Huertas A, editores. Diásporas, migrações, tecnologias da comunicação e identidades transnacionais. Belaterra: Instut de la Comunicació de la Universitat Autònoma de Barcelona, 2012. p. 433-48.

38. Escudero C. Imprensa de comunidades imigrantes de São Paulo e identidade: estudo dos jornais ibéricos Mundo Lusíada e Alborada [dissertação]. São Bernardo do Campo: Universidade Metodista de São Paulo; 2007.

39. Escudero C. Comunidades em festa: a construção e expressão das identidades sociais e culturais do imigrante nas celebrações das origens [tese]. Rio de Janeiro: Universidade Federal do Rio de Janeiro; 2017.

40. Escudero C, El-Hajji M. Latino immigrants communities in São Paulo and their web diasporic communication. In: The Migration Conference; 2019 June 18-20; Bari, Italy.

41. Peruzzo CMK. Conceitos de comunicação popular, alternativa e comunitária revisitados e as reelaborações no setor. Palabra Clave [Internet]. 2009 ago. [citado em 2019 jul. 22];12(2): 46-61. Disponível em: https://bit.ly/2LOPQNQ.

42. Carta de Ottawa 1986 [Internet]. Primeira Conferência Internacional sobre Promoção da Saúde [citado em 2019 nov. 4]. Disponível em: https://bit.ly/2OrxNCP.

43. Equipe de Base Warmis Convergência das Culturas. Quem somos [Internet]. São Paulo: a Equipe; [2016?] [citado em 2019 jul. 19]. Disponível em: http://www.warmis.org/quem-somos.html.

44. Campanha "No a la violência en el parto" [Internet]. São Paulo: Equipe de Base Warmis Convergência das Culturas; 2014 [citado em 2019 jul. 19]. Disponível em: http://www.warmis.org/projetos/no-a-laviolencia-en-el-parto.html.

45. Associação Nacional de Saúde (ANS). "Programa Parto Adequado não é \#PLdaMorteMaterna" [Internet]; 2019 [citado em 2019 jul. 5]. Disponível em: https://bit.ly/2DC]i43.

46. Colucci C. Projeto quer cesárea sem indicação clínica a gestantes do SUS: Para a deputada de SP Janaina Paschoal (PSL), proposta dá voz a usuárias que passam por violência obstétrica [Internet]. Folha de S.Paulo (Grupo Folha); 2019 jun. 11:Equilíbrio e Saúde [citado em 2019 jul. 15]. Disponível em: https://www1.folha.uol.com.br/equilibrioesaude/2019/06/projeto-quer-cesarea-sem-indicacaoclinica-a-gestantes-do-sus.shtml.

47. Posicionamento da SOGESP em relação ao PL 435/2019 [Internet]. São Paulo: Sogesp; 2019 [citado em 2019 jul 20]. Disponível em: https://www.sogesp.com.br/noticias/posicionamento-da-sogesp-emrelacao-ao-pl-4352019. 
48. Nota sobre o PL da cesárea [Internet]. São Paulo: Sindicato dos Psicólogos de São Paulo; 2019 [citado em 2019 jul 20]. Disponível em: http://www.sinpsi.org/index.php/noticia/index/id/6904.

49. Cremesp se opõe à vilanização da prática cirúrgica obstétrica consagrada pela ciência [Internet]. São Paulo: Cremesp; 2019 [citado em 2019 jul. 15]. Disponível em: http://www.cremesp.org. br/?siteAcao $=$ NoticiasC\&id $=5397$.

50. Cremesp se opõe à vilanização da prática cirúrgica obstétrica consagrada pela ciência [Internet]. São Paulo: Cremesp; 2019 [Notícias] [citado em 2019 jul. 15]. Disponível em: http://www.cremesp.org. br/?siteAcao $=$ NoticiasC\&id $=5397$. 